\title{
WETLAND MAPPING WITH SAR/QUAD-POL DATA ACQUIRED DURING TANDEM-X SCIENCE PHASE
}

\author{
M. Mleczko ${ }^{\text {a }}$, M. Mroz ${ }^{\text {a }}$, M. Fitrzyk ${ }^{\text {b }}$ \\ ${ }^{a}$ UWM Olsztyn, Department of Photogrammetry and Remote Sensing, 10-719 Olsztyn, ul. Oczapowskiego 1, Poland - \\ (magdalena.mleczko, marek.mroz)@uwm.edu.pl \\ ${ }^{\mathrm{b}}$ European Space Agency, ESRIN, Via Galileo Galilei, 00044 Frascati, Italy - magdalena.fitrzyk@esa.int
}

KEY WORDS: TanDEM-X, wetland mapping, Quad-Pol, Alt-Pol

\begin{abstract}
:
The aim of this study was to exploit fully polarimetric SAR data acquired during TanDEM-X - Science Phase (2014/2015) over herbaceous wetlands of the Biebrza National Park (BbNP) in North-Eastern Poland for mapping seasonally flooded grasslands and permanent natural vegetation associations. The main goal of this work was to estimate the advantage of fully polarimetric radar images (QuadPol) versus alternative polarization (AltPol) modes. The methodology consisted in processing of several data subsets through polarimetric decompositions of complex quad-pol datasets, classification of multitemporal backscattering images, complementing backscattering images with Shannon Entropy, exploitation of interferometric coherence from tandem operations. In each case the multidimensional stack of images has been classified using ISODATA unsupervised clustering algorithm. With 6 QUAD-POL TSX/TDX acquisitions it was possible to distinguish correctly 5 thematic classes related to their water regime: permanent water bodies, temporarily flooded areas, wet grasslands, dry grasslands and common reed. This last category was possible to distinguish from deciduous forest only with Yamaguchi 4 component decomposition. The interferometric coherence calculated for tandem pairs turned out not so efficient as expected for this wetland mapping.
\end{abstract}

\section{INTRODUCTION}

The hundreds of scientific papers, reports and books have been published on remote sensing of wetlands since decades. The research effort stems from, and it is still justified by, the importance of wetlands in biosphere functioning and biodiversity conservation. Wetlands functions and values are enumerated briefly by R. Tiner in (Tiner, Lang, Klemas 2015). The main functions of wetlands are: water storage, nutrient retention, carbon sequestration, sediments retention, streamflow maintenance, etc. Many factors interact to produce areas of wetlands and influence the types of plants that can colonize such sites. About 15 major types of wetlands can be distinguished around the globe and many wetland classification systems have been developed by various organizations. One of the most known is Ramsar international wetland classification. Wetlands mapping, inventory and monitoring became quickly one of the main concerns of the national and international organizations responsible for natural resources, sustainable development and quality of life. Remote sensing techniques have a great potential for observations of these difficult or often inaccessible areas. Passive remote sensing technologies (VNIR/SWIR) have done a great service in wetlands mapping and monitoring till nowadays but two major factors turned out to be the obstacles in repetitive, regular and "deeper" inspection of the wetlands. The first - clouds cover. The second measurements of the reflectance in VNIR/SWIR spectral region are the measurements from the first encountered surface. No "penetration into" is possible.

The last decades microwave (radar) technologies became largely exploited in wetland remote sensing due to their all-weather imaging ability and sensibility to specific features of the wetlands i.g. vegetation structure (types, species, biomass,...), water content in soils and plants, surface roughness determined by vegetal cover. Open water surfaces are also a subject of mapping and monitoring as a part of wetlands or the results of flooding (Hahmann and Wessel 2010, Horrit et al. 2001). In that case wind and/or rain can unfortunately introduce roughness disturbing purely specular reflection of microwaves from calm water surface.

Different scattering mechanisms (single, double bounce, volume scattering) resulting from plants amount and geometry and their level of submersion at given moment determine specific radar return in terms of amplitude, phase and polarization degree. The vegetation canopy penetration by microwaves allows for mapping of flooded vegetation as a result of enhanced backscatter from a double-bounce scattering mechanism (Brisco 2015, Brisco et al. 2011, Hong \& Wdowinski 2014). The nonflooded vegetation is often producing so called volume scattering, diffuse and weaker than double-bounce. The most advanced techniques allowing to "split" or "isolate" different scattering mechanisms from complex backscattered echoes are polarimetric decompositions. Some decomposition techniques such as the Cloud-Pottier, Freeman-Durden, Pauli, Yamaguchi, Touzi have been implemented in commercial or open source image processing packages. Besides of decompositions of fully polarimetric data (quad-pol) an interesting approach has recently been proposed for flooded vegetation mapping Shannon Entropy parameter (e.g. Betbeder et all. 2014, 2015) in case of dual-pol imaging. For delineating open water from the neighbouring upland multiple pairs of images taken at dual $\mathrm{HH} / \mathrm{HV}$ polarizations are often required both for good contrast (HH) and less sensitivity to surface roughness (HV). The differences in imaging angles have been also exploited as factors having influence on the penetration depth in vegetal cover and in consequence on scattering mechanisms proportions. Another interesting aspect of flooded vegetation mapping with SAR is interferometric coherence (Hong \& Wdowinski 2015). The achieved results of mapping and/or monitoring based on classification of the multitemporal stack of 
images are often site-specific. The same methods and algorithms used in different geographic (vegetation types) and hydrological context (dynamics of water level changes, stagnation period) can give different thematic results.

\subsection{Aim of the study and methodological approach}

The aim of this study was to exploit fully polarimetric SAR data acquired during TanDEM-X - Science Phase (2014/2015) over herbaceous wetlands of the Biebrza National Park (BbNP) in North-Eastern Poland for mapping seasonally flooded grasslands and permanent natural vegetation associations. The TanDEM-X Science Phase was the unique temporal opportunity to gather quad-pol X-band SAR images free of charge and to compare their thematic potential with standard imaging TSX/TDX products available operationally for the end-users. In this specific case the end-users would be BbNP managers dealing with endangered wetland ecosystem in the middle basin of the Biebrza valley due to lack of water. The main goal of this work was to estimate the advantage of fully polarimetric radar images (QuadPol) versus alternative polarization (AltPol) modes. Multitemporal, polarimetric SAR X-band data is supposed to deliver better thematic information on spring flooding extent (area and period of water stagnation) and vegetation types submerged (or not) comparing to standard TSX-X/SAR detected or complex products (backscattering at different polarizations in dual-pol mode, i.e. $\mathrm{HH} / \mathrm{HV}, \mathrm{HH} / \mathrm{VV}$, $\mathrm{VV} / \mathrm{VH})$. The methodology consisted in processing of several data subsets, their thematic classifications and accuracy assessment as follows:

- polarimetric decompositions and classifications of complex quad-pol datasets,

- classification of multitemporal backscattering images (sigma nought time series at $\mathrm{VV} / \mathrm{VH} / \mathrm{HV} / \mathrm{HH}$ polarizations),

- complementing backscattering images with Shannon Entropy parameter possible to retrieve in dual-pol mode (Single Receive Antenna),

- exploitation of interferometric coherence between two images acquired during tandem operations.

An important question to answer in this study was whether and how changing water level can contribute to vegetation types recognition and mapping in this specific context.

\section{MATERIALS AND METHODS}

\subsection{Study site}

The investigated area is a part of the Middle Basin of the Biebrza Valley (NE Poland), a large depression more than 100 km long.

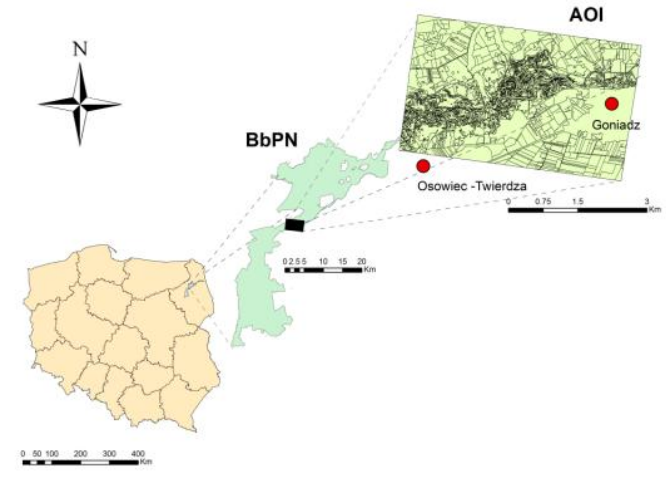

Figure 1. Location of the study site.
"Hydrogenic dependent habitats cover $40 \%$ of the valley`s total area. Some of the most dominating and ecologically valuable vegetation associations include sedge, sedge-moss, reed communities, and mineral islands. Several canals constructed in the $19^{\text {th }}$ century have changed hydrological regimes of this part of the valley, leading to a permanent drop in the water table and drainage of the peatlands. Water ecosystems are riverbeds and oxbows or old riverbeds. This decrease of the ground water level gave way to many semi-natural communities the most common being meadow type associations" (Infos from http://www.biebrza.org.pl). The main vegetation species growing on the test site are listed in the table 1 .

\begin{tabular}{|l|l|}
\hline \multicolumn{1}{|c|}{ English name } & \multicolumn{1}{c|}{ Latin name } \\
\hline Bur-reed & Sparganietum ramosi \\
\hline Sweet-grass & Glycerietum maximae \\
\hline Reed canary & Phalaris arundinacea \\
\hline Lakeshore bulrush & Scirpetum lacutris \\
\hline Bulrush & Typhetum latifoliae \\
\hline Common reed & Phragmitetum australis \\
\hline Sedge & Caricetum gracilis \\
\hline Dogwood & Cornus sericea \\
\hline Willow scrub & Salix \\
\hline
\end{tabular}

Additionally due to climate change the lack of snow in winter and weak rains during the remaining part of the year lead to severe ecological consequences: the worsening of live conditions of the wading birds and the ichthyofauna in the oxbows. Thus for this area the information on flooding extent variability is valuable information itself because flooded natural grasslands or meadows are the vital part of the valley.

\subsection{Data}

The Tandem-X Science Phase (TDX/SP) was dedicated to the demonstration of innovative techniques and experiments (...) in order to foster the development of new methods and applications (TD-PD-PL_0032TanDEM-X_Science_Phase, 2014). The primary objective of the TanDEM-X mission is the generation of a worldwide high precision Digital Elevation Model (DEM). The operational scenario requires special orbital (helix) formation of the satellites TSX/TDX permitting acquisitions for Cross-Track Interferometry or Along-Track Interferometry. Interferometric data acquisitions can be achieved operationally from two modes: Bistatic and Pursuit Monostatic combined with three imaging modes: StripMap, ScanSAR and Spotlight. The acquisition of a fully polarimetric coherent scattering matrix is enabled in Dual Receive Antenna (DRA) mode by the electronically split antenna. Only in the StripMap mode fully polarimetric coregistered (CoSSC) products for the bistatic and pursuit monostatic mode are available.

Science Phase Timeline is cited in table 4.3. of the above mentioned document TD-PD-PL_0032. More than 20 products have been acquired for the whole test area during TDX/SP but only 6 amongst them were chosen for described study. These acquisitions cover 2-month period of spring flooding and dynamic vegetation development on the wetlands. All processed Quad-Pol images have been registered in StripMap, Bistatic Interferometric Mode, Beam_Id - stripFar_009, at incidence angle of 36 degrees from ascending orbit no. 9 with slant range resolution of $1.2 \mathrm{~m}$ and azimuth resolution of $6.6 \mathrm{~m}$. Estimated Mean Perpendicular Cross Track Baselines were 1 924m, and 
Estimated Mean Along Track Baselines were 298m. Other acquisition parameters are listed in the table 2 .

\begin{tabular}{|c|c|}
\hline Date of acquisition & Master satellite / bistaticActive \\
\hline $25 / 04 / 2015$ & TDX-1 \\
\hline $06 / 05 / 2015$ & TSX-1 \\
\hline $17 / 05 / 2015$ & TSX-1 \\
\hline $08 / 06 / 2015$ & TSX-1 \\
\hline $19 / 06 / 2015$ & TSX-1 \\
\hline $30 / 06 / 2015$ & TDX-1 \\
\hline
\end{tabular}

Table 2. Master satellite in bistatic pair for successive dates of acquisitions.

\subsection{Image pre-processing}

Image pre-processing workflow shown in the figure 2 explains all consecutive steps in TSX/TDX data import and preparation for further studies.

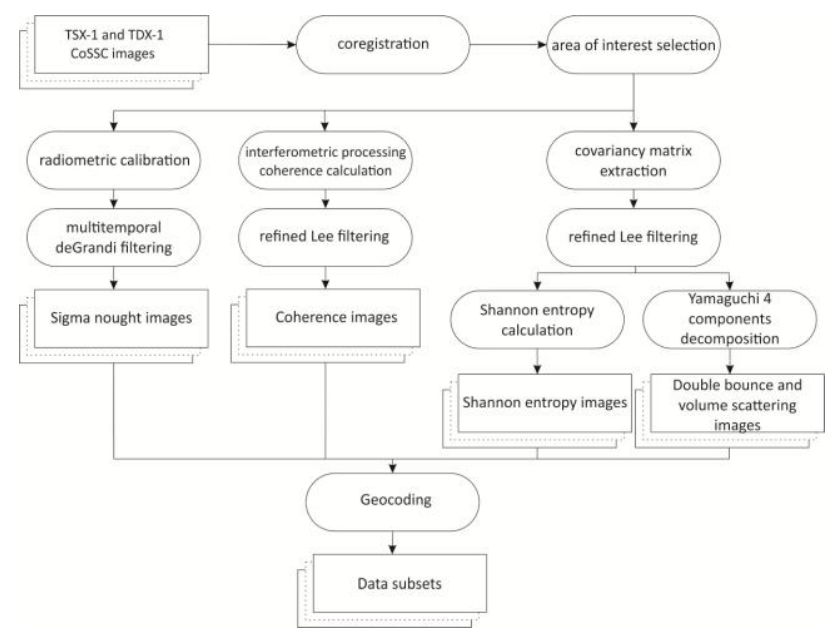

Figure 2. Workflow of TSX/TDX data preprocessing.

The CoSSC images have been processed using SARScape 5.0 (SARMAP) \& PolSARPro 5.0 (PSP) software (Rennes University). For data import, coregistration, radiometric calibration, selection of test area, multitemporal de Grandi filtering and interferometric processing including coherence calculation SARScape software running in ENVI (Harris) environment has been used. Two polarimetric decompositions (Shannon Entropy and Yamaguchi 4 components) preceded by refined Lee speckle filtering have been performed using PSP. The results of the pre-processing form four stacks of images respectively: 1). Two Yamaguchi components: double bounce and volume scattering, 2). Shannon Entropy images, 3). Coherence images, 4). Sigma nought in $\mathrm{dB}$ at VV/VH/HV/HH polarizations despeckled. All these files have been the subject of further thematic processing as described in subheading 2.4.

\subsection{Methodological approach for multitemporal TSX/TDX data analyses.}

The methodology distinguishes two approaches. One consists in exploitation of polarimetric decompositions possible to perform based on TSX/TDX EXPERIMENTAL Products. For comparison another one has been based on STANDARD Products taking advantage of tandem mode in order to extract interferometric coherence between two acquisitions very close in time. In each case the multidimensional stack of images has been classified using ISODATA unsupervised clustering algorithm as implemented in ENVI 5.0 package. The steering parameters of classification have to be carefully analyzed because of the data heterogeneity. The default parameters are suggested for one byte per pixel coding and suppose the pixel values have normal distribution. For this classification the following parameters turned out to be appropriate: minimum number of classes -8 , maximum -12 , maximum iterations -30 , change threshold $-1 \%$, minimum pixels in class -100 , maximum standard deviation -1 , minimum class distance -3 , maximum merge pairs -2 .

Especially the initial number of clusters (classes) has to be reasonably declared. The decision has been taken after analyzing table 1 and content of particular images showing the contrast between different objects. In order to better predict a priori the correspondence between clusters and thematic categories for each pair of vegetation types listed in table 1 the separability measure in form of Jeffries-Matussita Distance had been calculated. This operation is not a vital element of the methodology adopted here and it will not be discussed in details. It was only a hint for operator regarding further stage of class aggregation. One thematic category - deciduous flooded forest - seems to be specific from wetlands mapping point of view. Some researchers exclude a priori this category from the list of land cover / vegetation associations (e.g. Betbeder 2015) supposing that their location is known and backscattering features could worsen the overall accuracy of classification. This approach seems to be justified but in some cases when vegetation succession has to be analyzed over many years it is interesting to check the possibility of their identification amongst other wetland vegetation.

In order to verify the correctness of clusters assigning and thematic labeling many data from field visits and aerial orthophotomaps have been used. Statistically representative number of check parcels has been used for matching matrix (MM) construction and elaboration of wetland map. Matching matrix represents the same idea as confusion matrix widely used in supervised classifications. The last synthetic parameter of accuracy assessment was the Kappa Index of Agreement issued from MM.

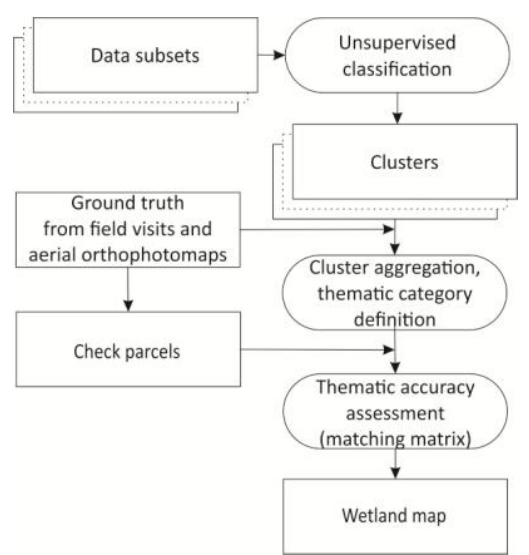

Figure 3. Workflow of thematic processing of the data subsets.

\section{RESULTS - THEMATIC CLASSIFICATIONS OF IMAGE SUBSETS}

In order to facilitate the reader to follow our results and comments it is necessary to introduce some symbols and abbreviations describing the data subsets:

- SE - Shannon Entropy, 
- SN - Sigma Nought (detected products in $\mathrm{dB}$ ),

- Coh - images of coherence,

- YAM4 - decomposition proposed by Yamaguchi (4 components decomposition)

For 2 data subsets $(\mathrm{A}, \mathrm{B})$ extracted from 6 Experimental QuadPol acquisitions:

A. $=$ YAM4

B. $=\mathrm{SN}$

it was possible to distinguish only 6 thematic categories: permanent water bodies, temporarily flooded areas, wet grasslands, dry grasslands, common reed and deciduous forest.

For these categories the synthetic measures of accuracy of classification is shown in the table 3 .

\begin{tabular}{|c|c|c|}
\hline Polarization set & HH-HV-VH-VV & $\begin{array}{c}\text { HH-HV- } \\
\text { VH-VV }\end{array}$ \\
\hline Subset & YAM4 & SN \\
\hline $\begin{array}{c}\text { Number of input } \\
\text { images for } \\
\text { clustering }\end{array}$ & $\begin{array}{c}12 \\
\text { (6 dates x 2 } \\
\text { components) }\end{array}$ & $\begin{array}{c}24 \\
\text { (6 dates x } \\
\text { 4 images) }\end{array}$ \\
\hline $\begin{array}{c}\text { Overall Accuracy } \\
\text { [\%] }\end{array}$ & 76.57 & 66.96 \\
\hline $\begin{array}{c}\text { Kappa Index of } \\
\text { Agreement }\end{array}$ & 0.71 & 0.60 \\
\hline
\end{tabular}

Table 3. The results of Accuracy Assessment for subsets A,B extracted from Experimental Quad-Pol data for 6 classes.

Figure 4 represents classification results of the subset A showing higher Overall Accuracy and Kappa Index.

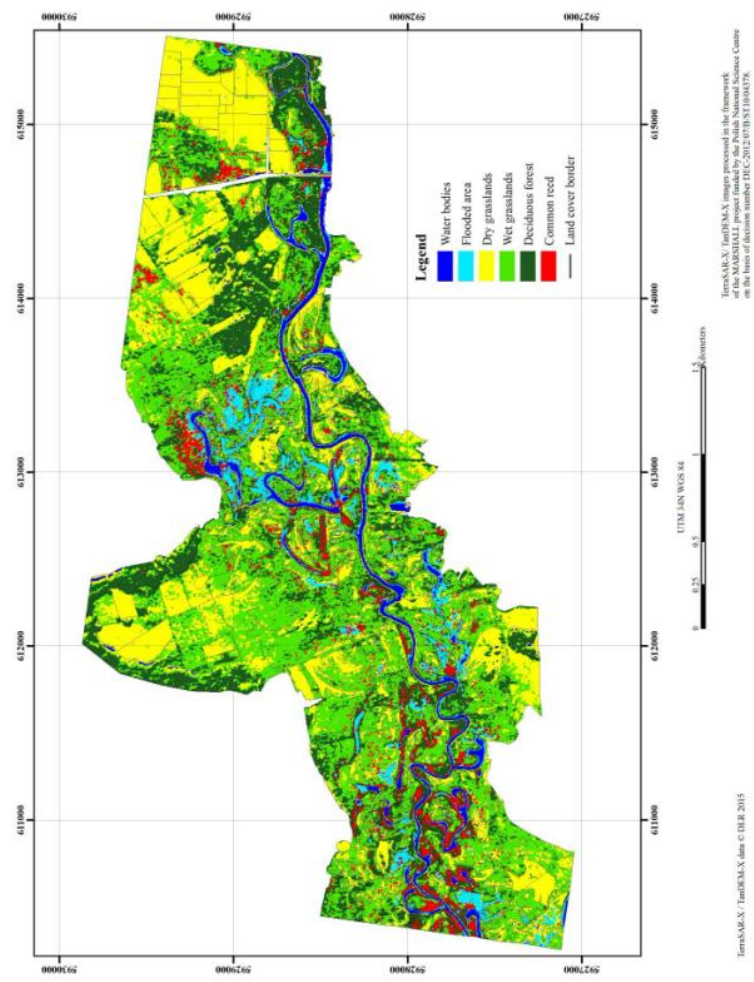

Figure 4. Thematic classification of AOI with Yamaguchi decomposition.

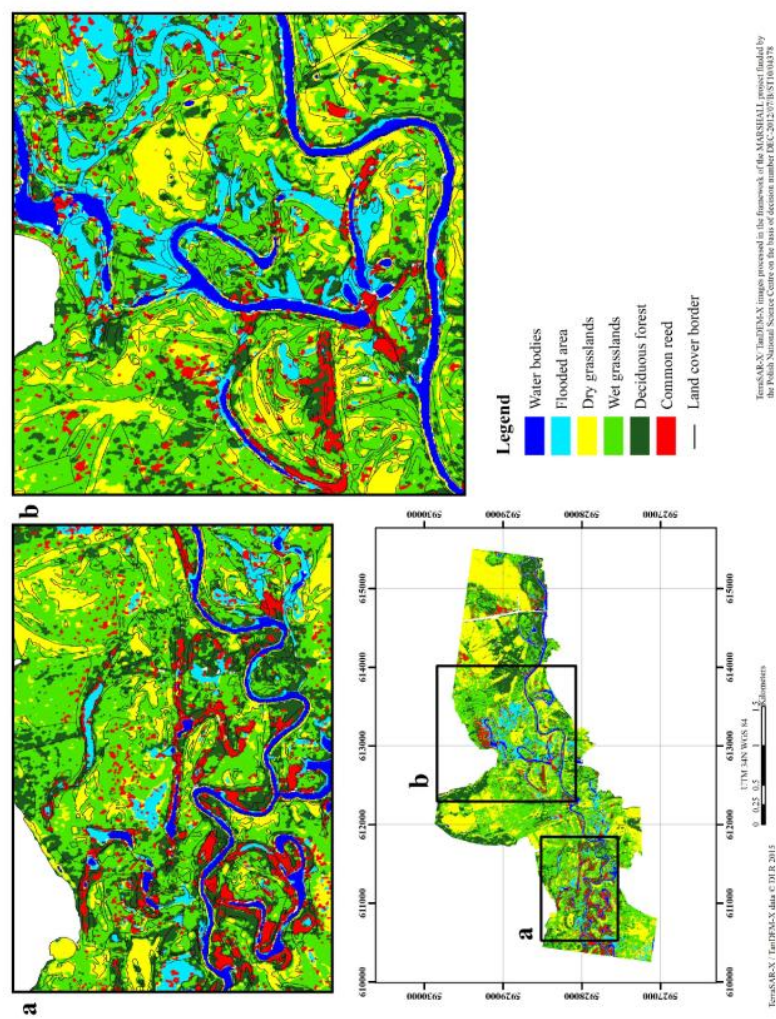

Figure 5. Zooming of parts of the fig.4.

As mentioned in subheading 2.4. thematic class "deciduous forest" can sometimes be problematic. This case turned out to be true in this study. The clustering based on Shannon Entropy time series (subset C) was completely inefficient establishing the same cluster for "deciduous forest" and "common reed" classes. After excluding "forest" from the area of interest the accuracy of classification results for 5 classes (permanent water bodies, temporarily flooded areas, wet grasslands, dry grasslands, common reed) increased. See table 4.

\begin{tabular}{|c|c|c|c|}
\hline Polarization set & $\begin{array}{c}\text { HH-HV- } \\
\text { VH-VV }\end{array}$ & $\begin{array}{c}\text { HH-HV- } \\
\text { VH-VV }\end{array}$ & $\begin{array}{c}\text { HH-HV-VH- } \\
\text { VV }\end{array}$ \\
\hline Subset & YAM4 & SE & SN \\
\hline $\begin{array}{c}\text { Number of input } \\
\text { images for } \\
\text { clustering }\end{array}$ & 12 & 6 & 24 \\
\hline $\begin{array}{c}\text { Overall Accuracy } \\
{[\%]}\end{array}$ & 89.06 & 76.93 & 88.96 \\
\hline $\begin{array}{c}\text { Kappa Index of } \\
\text { Agreement }\end{array}$ & 0.85 & 0.70 & 0.85 \\
\hline
\end{tabular}

Table 4. The results of Accuracy Assessment for subsets A,B,C extracted from Experimental Quad-Pol data for 5 thematic classes.

The last analyzed subset (D) contains Standard dual-pol images complementing with "derivative" products - Shannon Entropy and coherence. 


\begin{tabular}{|c|c|c|c|}
\hline Subset & HH-HV & HH-VV & VV-VH \\
\hline $\begin{array}{l}\text { SE }(6 \text { bands }) \\
\text { \{Overall Agreement / } \\
\text { Kappa }\}\end{array}$ & $\begin{array}{c}85.82 / \\
0.81\end{array}$ & $\begin{array}{c}80.76 / \\
0.75\end{array}$ & $\begin{array}{c}80.66 / \\
0.74\end{array}$ \\
\hline $\begin{array}{l}\text { SN (12 bands) } \\
\text { \{Overall Agreement / } \\
\text { Kappa }\}\end{array}$ & $\begin{array}{c}91.12 / \\
0.88\end{array}$ & $\begin{array}{l}88.66 / \\
/ 0.85\end{array}$ & $\begin{array}{c}83.50 / \\
0.78\end{array}$ \\
\hline $\begin{array}{l}\mathrm{SN}+\text { Coh }(24 \text { bands }) \\
\{\text { Overall Agreement } / \\
\text { Kappa }\}\end{array}$ & $\begin{array}{c}83.27 / \\
0.78\end{array}$ & $\begin{array}{c}88.65 / \\
0.85\end{array}$ & $\begin{array}{c}78.58 / \\
0.72\end{array}$ \\
\hline
\end{tabular}

Table 5. The results of Accuracy Assessment for subset D extracted from Standard Dual-Pol data for 5 thematic classes.

\section{CONCLUSIONS}

The results of wetland mapping obtained in this study refer to the quite specific site of flooded grasslands and river lakes (connected or isolated oxbows). With 6 QUAD-POL TSX/TDX acquisitions it was possible to distinguish correctly 5 thematic classes related to their water regime: permanent water bodies, temporarily flooded areas, wet grasslands, dry grasslands and common reed. This last category was possible to distinguish from deciduous forest only with Yamaguchi 4 component decomposition. This decomposition has extracted from multitemporal complex data the double bounce and volume scattering mechanisms specific to that category of vegetation. With Standard Dual-Pol products the best results of classification have been achieved at $\mathrm{HH} / \mathrm{HV}$ polarizations both for amplitude time series and Shannon Entropy. The interferometric coherence calculated for tandem pairs turned out not so efficient as expected for this wetland mapping. The further research will take into account also the remaining TSX/TDX Quad-Pol data acquired in summer 2015.

\section{ACKNOWLEDGEMENTS}

The authors acknowledge German Space Agency DLR for providing TerraSAR-X / TanDEM-X Quad-Pol images in the framework of NTI_POLI 6756 " Oxbow Plus" Proposal.

Publication prepared in the framework of the MARSHALL project funded by the Polish National Science Centre on the basis of decision number DEC-2012/07/B/ST10/04378.

\section{REFERENCES}

Betbeder, J., Rapinel, S., Corgne, S., Pottier, E., \& HubertMoy, L. (2015). TerraSAR-X dual-pol time-series for mapping of wetland vegetation. ISPRS Journal of Photogrammetry and Remote Sensing, pp.90-98.

Brisco, B. (2015). Mapping and Monitoring Surface Water and Wetlands with Synthetic Aperture Radar. W R. W. Tiner, M. W. Lang, \& V. V. Klemas, Remote Sensing of Wetlands Applications and Advances (pp.119-135). CRC PressTaylor \& Francis Group.

Eltoft, T., Doulgeris, A. P., \& Anfinsen, S. N. (2012). Analysis of textured PolSAR data by Shannon entropy. Proceedings of IGARSS2012 pp. 1449-1452.
Fritz, T., and Eineder M., (2013) TerraSAR-X ground segment, SAR basic product specification document (TX-GS-DD-3302), Issue 1.9 http://sss.terrasar-x.dlr.de/ (15 Apr 2016).

Hahmann, T., \& Wessel, B. (2010, 06 7-10). Surface water body detection in high-resolution TerraSAR-X data using active contour models. Proceedings of the 8th European Conference on Synthetic Aperture Radar, pp. 1-4.

Hajnsek I., Busche T.E., (2014) "TanDEM-X Ground Segment. Announcement of Opportunity: TanDEM-X Science Phase" (TD-PD-PL-0032) Issue $1.0 \mathrm{http} / / /$ tandemx-science.dlr.de/ (15 Apr 2016).

Hong, S.-H., \& Wdowinski, S. (2014). Double-Bounce Component in Cross-Polarimetric SAR From a New Scattering Target Decomposition. IEEE Transactions on Geoscience and Remote Sensing (52).

Horrit, M. S., Mason, D. C., \& Luckman, A. J. (2001). Flood boundary delineation from synthetic aperture radar imagery using a statistical active contour model. International Journal of Remote Sensing(22), pp. 2489-2507.

White, L., Brisco, B., Dabboor, M., Schmitt, A., \& Prat, A. (2015). A collection of SAR Methodologies for Monitoring Wetlands. Remote Sensing, 7, 7615-7645. 